\title{
Comparison of the Morse Cone Connection with the Internal Hexagon and External Hexagon Connections Based on Microleakage - Review
}

\author{
Ana Beatriz Bueno Carlini Bittencourt, Clóvis Lamartine \\ de Moraes Melo Neto, Paulo Augusto Penitente, Eduardo Piza Pellizzer, \\ Daniela Micheline dos Santos, Marcelo Coelho Goiato \\ Department of Dental Materials and Prosthodontic, Araçatuba School of Dentistry, \\ São Paulo State University (UNESP), São Paulo, Brazil
}

Received March 4, 2021; Accepted August 22, 2021.

Key words: Morse taper dental implant-abutment connection - Dental abutments Bacteria - Dental implants - Microbiota - Prostheses and implants

\begin{abstract}
The gap formed at the abutment-implant interface brings about a bacterial colonization. In addition, a bacterial reservoir can be established within the implant. The build-up of microorganisms around the implant can cause soft tissue infections and bone loss around the implant, which can lead to implant failure. Our literature review aimed to evaluate the infiltration at the implant-abutment interface, comparing the Morse cone connection with the external hexagon and internal hexagon connections. A literature search using the PubMed database was performed on March 24, 2021. The search terms were combinations of "Morse cone" or "Morse taper" with each of the following terms (individually): "microleakage", "leakage", "infiltration", and "penetration". The inclusion criterion was in vitro studies comparing the Morse cone with the external hexagon and/or internal hexagon, based on infiltration at the implant-abutment interface. The exclusion criterion was the evaluation of microleakage at the implant-abutment interface after applying a sealant over this region. The search was expanded as needed. There was no limit on the year of publication, and only articles written in English were included. In addition, references cited in included articles were also included in this review when they were appropriate. This literature review concluded that, in most cases, the microleakage in the Morse cone connection was lower when compared with the external hexagon and internal hexagon connections.
\end{abstract}

Mailing Address: Prof. Marcelo Coelho Goiato, Department of Dental Materials and Prosthodontic, Araçatuba School of Dentistry, São Paulo State University (UNESP), José Bonifácio Street, 1193, Araçatuba, 16015-050, São Paulo, Brazil; Phone: +55 (18) 363632 37; e-mail: m.goiato@unesp.br 


\section{Introduction}

In implantology, implant-abutment connections have been used clinically for many decades (Scarano et al., 2016a). Basically, two connections are available: internal and external connections (Goiato et al., 2015). The external connection usually has an external hexagon on the implant platform, and the internal connection can be divided into internal hexagon, internal octagon, and Morse cone, which has been currently widely used (Goiato et al., 2015).

Even when the implant and abutment are connected correctly, a microgap is formed (Pereira et al., 2016); so, there is no implant connection that can provide a complete seal at the implant-abutment interface (Schmitt et al., 2014). In addition, this microgap can increase in size over time due to masticatory loads that can cause micromovements of the prosthesis components (Scarano et al., 2015; Pereira et al., 2016). Regardless of the type of connection, the implantabutment interface (with a microgap) is present and may be located at different depths of the bone crest (subcrestal, equicrestal or supracrestal), depending on the connection used (Dibart et al., 2005; Ricomini Filho et al., 2010; Verdugo et al., 2014).

The microleakage produced by a microgap between implant and abutment, allows the passage of acids, enzymes, bacteria (Verdugo et al., 2014) (commensal and/or pathogenic bacteria, especially anaerobic or microaerophilic species) (do Nascimento et al., 2012) and/or their metabolic products (Verdugo et al., 2014). Therefore, the microgap formed at the abutment-implant interface becomes a reservoir of microorganisms, and these microorganisms can still infiltrate into the implant (Ricomini Filho et al., 2010; Scarano et al., 2015; Mishra et al., 2017).

Bacterial penetration at the implant-abutment interface can occur under static conditions and during masticatory function (Scarano et al., 2015). The degree of union between abutment and implant, micromovements between them and the applied torque determine different amounts of bacterial movements (from outside to inside and vice and versa - "pump effect") in the different implant connections (Scarano et al., 2015).

Accumulation of microorganisms around the implant due to a microgap, can cause soft tissue infections (Scarano et al., 2015; Mishra et al., 2017) (causing bleeding, swelling and a bad odour) (Verdugo et al., 2014) and bone loss around the implant, which can lead to implant failure (Scarano et al., 2015; Mishra et al., 2017). According to Dibart et al. (2005) this situation occurs because the sustained activation of inflammatory cells promotes the formation and activation of osteoclasts, which can result in alveolar bone loss. Therefore, it is important to ensure the minimum presence of bacteria inside or around the implant-abutment junction (Dibart et al., 2005).

Our literature review is aimed to evaluate the infiltration at the implant-abutment interface, comparing the Morse cone connection with the external hexagon and internal hexagon connections. 


\section{Material and Methods}

A literature search using the PubMed database was performed on March 24, 2021. The search terms were combinations of "Morse cone" or "Morse taper" with each of the following terms (individually): "microleakage", "leakage", "infiltration", and "penetration". The inclusion criterion was in vitro studies comparing the Morse cone with the external hexagon and/or internal hexagon, based on infiltration at the implant-abutment interface. The exclusion criterion was the evaluation of microleakage at the implant-abutment interface after applying a sealant over this region. The search was expanded as needed. There was no limit on the year of publication, and only articles written in English were included. In addition, references cited in included articles were also included in this review when they were appropriate. Twelve articles on the specific purpose of this review were included in this study (Ricomini Filho et al., 2010; do Nascimento et al., 2012, 2015; Jaworski et al., 2012; Tripodi et al., 2012; D'Ercole et al., 2014; Sahin and Ayyildiz, 2014; Verdugo et al., 2014; Scarano et al., 2015; Pereira et al., 2016; da Silva-Neto et al., 2017; de Sousa et al., 2019). The other articles included aimed to contextualize the reader and discuss the review.

\section{Implant connections}

External hexagon connection

The external hexagon was the first connection system adopted in modern implantology by Brånemark (Brånemark et al., 1977; Brånemark, 1983; Ceruso et al., 2017) and was subsequently improved (Ceruso et al., 2017). Despite this, this type of connection has 3 disadvantages according to Verdugo et al. (2014):

1) There is little contact length between the restoration and the hexagonal part of the implant head $(0.7 \mathrm{~mm})$ (Verdugo et al., 2014).

2) The seating of the secondary component provides a degree of freedom between it and the main component; this allows a degree of rotation between the external hexagon of the platform and the internal hexagon of the restoration component (Verdugo et al., 2014).

3) There is great tension in the screw connection. The screw is essentially the only resistance device in the connection unit, so all the force generated due to the micromovements is released on the screw (Verdugo et al., 2014). As a result, the screw tends to loosen and/or fracture relatively easily (Verdugo et al., 2014).

\section{Internal hexagon connection}

The connection of the internal hexagon was developed to improve factors such as stress distribution and contact area between the implant and the secondary component (Verdugo et al., 2014; Ceruso et al., 2017).

According to Verdugo et al. (2014):

In the internal hexagon connection, the hexagon and the screw pass into the implant body and the length of the hexagon increases to $1.2 \mathrm{~mm}$; thus, the 
prosthetic component is more stable, even without the fixing screw (Verdugo et al., 2014). The greater the length of contact between the implant and the external component, the lower the tension for the fixation screw, reducing the probability of loosening the screw (Verdugo et al., 2014). The force generated by the micromovements in this type of connection is dissipated to the walls adjacent to the implant hexagon and in a lower degree to the screw (Verdugo et al., 2014). This lower tension on the fixing screw can also be seen in the Morse cone connection (Verdugo et al., 2014).

\section{Morse cone connection}

In 1864, this connection was developed by Stephen A. Morse, and since has been used worldwide to connect drilling machines to a removable rotating drill piece (Ranieri et al., 2015; Macedo et al., 2016). The basic principle of this system is "a cone within a cone" (Hernigou et al., 2013; Ranieri et al., 2015). In dentistry, in addition to the mechanical locking of the Morse cone system, a screw retention is added to this system (Vinhas et al., 2020). The taper angle of the Morse cone system can be 8,11 or $16^{\circ}$ (Merz et al., 2000; Khorshidi et al., 2016; Vinhas et al., 2020). It is also worth mentioning that the Morse cone implant accepts different abutment platforms (Macedo et al., 2016).

\section{Review}

According to Scarano et al. (2015) several techniques have been used, in vitro, to evaluate the sealing ability of the implant-abutment interface, such as, bacteria, bacterial toxins, dyes (toluidine blue and gentian violet), gas, saliva and etc.

\section{Morse cone versus external hexagon}

Verdugo et al. (2014) evaluated microleakage (methylene blue) at the implantabutment interface by comparing the Morse cone $\left(M G \operatorname{lnHex}{ }^{\circledR}\right)$ with the external hexagon (Osseous $\mathrm{MG}^{\circledR}$ ). Verdugo et al. (2014) observed that after mechanical and thermal cycling $(2,000$ cycles of $10 \mathrm{k}$ every $0.5 \mathrm{~s}$; and two sessions of 300 cycles in water at $5{ }^{\circ} \mathrm{C}$ for $5 \mathrm{~s}$ and then at $50^{\circ} \mathrm{C}$ for $5 \mathrm{~s}$ ), regardless of the torque used (hand tightening, $20 \mathrm{~N}$ and $30 \mathrm{~N}$ [recommended by the manufacturer]), the Morse cone showed significantly less microleakage when compared with external hexagon (the microleakage was observed with an optic microscopy). Furthermore, in this study it was observed that the microgap formed between abutment and Morse cone implant was $2-3 \mu \mathrm{m}$, while the microgap formed by the external hexagon connection was $10 \mu \mathrm{m}$ (Verdugo et al., 2014).

Jaworski et al. (2012) compared the Morse cone connection (10 Ncm of torque Titamax CM, Neodent ${ }^{\circledR}$ ) with the external hexagon connection (32 Ncm of torque Titamax Ti cortical, Neodent ${ }^{\circledR}$ ) based on microleakage (Escherichia coli). Both torques were applied according to the manufacturer's recommendations (Jaworski et al., 2012). This comparison was made by a microbiological analysis (Jaworski 
et al., 2012). Sixty percent of the samples in the external hexagon group were contaminated and $30 \%$ of the samples in the Morse cone group were contaminated. Therefore, Jaworski et al. (2012) concluded that both connections showed leakage, but the Morse cone connection provided a better bacterial seal than the external hexagon connection.

Scarano et al. (2015) compared the leakage of toluidine blue between the external hexagon connection and the Morse cone connection using mechanical cycling of $1 \times 10^{6}, 3 \times 10^{6}$ and $6 \times 10^{6}$. The abutments were connected to the implants according to the manufacturer's recommendations (Implacil - De Bortoli ${ }^{\circledR}$ ) (Scarano et al., 2015). They observed that no significant differences were detected between these connections when the lowest cycling was used (Scarano et al., 2015). However, a difference was observed when the samples were loaded with $3 \times 10^{6}$ and $6 \times 10^{6}$ cycles, with significantly lower toluidine leakage in the Morse cone group (Scarano et al., 2015).

Ricomini Filho et al. (2010) compared these connections: external hexagon with universal post, Morse taper with universal post (MT-1), Morse taper with universal post through bolt, and locking taper with standard abutment (MT-2), based on bacterial infiltration. The torque of $32 \mathrm{Ncm}$ was used for external hexagon and Morse cone with universal post, and the torque of $15 \mathrm{Ncm}$ was used for Morse cone with universal post through bolt (all torques were applied according to the manufacturers) (Ricomini Filho et al., 2010). Samples (implant-abutment) were subjected to a thermal cycling regimen $\left(1,000\right.$ cycles of $5{ }^{\circ} \mathrm{C}$ and $\left.55^{\circ} \mathrm{C}\right)$ and to mechanical fatigue (1.0 million cycles, $1.0 \mathrm{~Hz}, 120 \mathrm{~N}$ ) (Ricomini Filho et al., 2010). The samples were immersed in Tryptic Soy + Yeast Extract broth containing Streptococcus sanguinis and incubated at $37^{\circ} \mathrm{C}$ and $10 \% \mathrm{CO}_{2}$ for $72 \mathrm{~h}$ (Ricomini Filho et al., 2010). Then, an evaluation of the microleakage was performed with and without thermocycling (Ricomini Filho et al., 2010). The external hexagon groups showed $0 \%$ bacterial penetration regardless of the application of thermomechanical cycling or not (Ricomini Filho et al., 2010). The Morse cone groups without thermomechanical cycling had a penetration rate of 40\% (MT-2) and 60\% (MT-1); and the Morse cone groups after thermomechanical cycling had a penetration rate of 50\% (MT-2) and 67\% (MT-1) (Ricomini Filho et al., 2010).

Pereira et al. (2016) evaluated the removal torque and the biofilm penetration at the implant-abutment interface of the Morse cone and external hexagon after fatigue $\left(50 \mathrm{~N}\right.$ at $30^{\circ} \mathrm{C}$ and under 500,000 cycles at $1.2 \mathrm{~Hz}$ in growth medium containing human saliva for 72 hours). Before mechanical cycling, the Morse cone abutment screws were tightened using a torque of $15 \mathrm{Ncm}$, while the external hexagon abutments were tightened using a torque of $32 \mathrm{Ncm}$, according to the manufacturer's recommendation (Neodent ${ }^{\circledR}$ ) (Pereira et al., 2016). Pereira et al. (2016) concluded that the optical density of biofilms and the mean CFU (colonyforming unit) value were significantly lower in the Morse cone group than in the external hexagon group. The mean values of removal torque were significantly 
lower for both connections (Morse cone and external hexagon) after fatigue (Pereira et al., 2016). The gap sizes before fatigue were $1.7 \pm 0.4 \mu \mathrm{m}$ (Morse cone) and $1.5 \pm 0.4 \mu \mathrm{m}$ (external hexagon), and after fatigue were $3.2 \pm 0.8 \mu \mathrm{m}$ (Morse cone) and $8.1 \pm 1.7 \mu \mathrm{m}$ (external hexagon) - significant increase in both cases (Pereira et al., 2016).

de Sousa et al. (2019) compared the Morse cone connection $(20 \mathrm{Ncm})$ with the external hexagon connection $(30 \mathrm{Ncm}$ ) based on microleakage. Both torques were applied according to the manufacturer's recommendations (DSP Biomedical ${ }^{\circledR}$ ) (de Sousa et al., 2019). Through a microbiological evaluation, de Sousa et al. (2019) found that there was no significant difference in the bacterial growth of Enterococcus faecalis or Candida albicans or Enterococcus faecalis + Candida albicans between the Morse cone and external hexagon groups.

Morse cone versus internal hexagon

In the study by Sahin and Ayyildiz (2014), to measure the leakage at implantabutment interface, a modified fluid filtration method using deionized water with pressure was used. When comparing the Morse cone connection with the internal hexagon connection, both titanium abutments (torque of $25 \mathrm{Ncm}$ - manufacturer's recommendation), it was possible to verify that there was no significant difference regarding the microleakage or loss of torque between them (Sahin and Ayyildiz, 2014). However, when comparing Morse cone (titanium abutment/torque of $25 \mathrm{Ncm}$ - manufacturer's recommendation) with internal hexagon (zirconia abutment/torque of $25 \mathrm{Ncm}$ - manufacturer's recommendation), the internal hexagon connection showed a microleakage and torque loss significantly greater than the Morse cone connection (Sahin and Ayyildiz, 2014). Sahin and Ayyildiz (2014) speculated that microleakage causes the screw to loosen, removing torque values as microleakage increases. In addition, the removal torque values reached up to $91 \%$ of the initial tightening torque value $(25 \mathrm{Ncm})$ (Sahin and Ayyildiz, 2014).

D'Ercole et al. (2014) evaluated in a period of 28 days, the microbial leakage of the implant-abutment connection of the Morse cone and internal hexagon systems (Dentoflex ${ }^{\circledR}$ ). Ten specimens of Morse cone (group 1) and 10 of internal hexagon (group 2) implants were used (D'Ercole et al., 2014). The inner parts of 5 implants per group were inoculated with Pseudomonas aeruginosa and 5 implants per group with Aggregatibacter actinomycetemcomitans (D'Ercole et al., 2014). D'Ercole et al. (2014) used a microbiological method to evaluate microleakage. The result showed a high permeability related to bacterial leakage from the internal hexagon connection and the lower infiltration rates - although not significantly - of the Morse cone connection (D'Ercole et al., 2014). Tripodi et al. (2012) carried out a study similar to that carried out by D'Ercole et al. (2014), and Tripodi et al. (2012) obtained results similar to those observed in the study by D'Ercole et al. (2014). 
Morse cone versus external and internal hexagon connections

do Nascimento et al. (2012) evaluated the bacterial leakage from human saliva to the internal part of the implants along the implant-abutment interface under loaded $(500,000$ cycles at $120 \mathrm{~N})$ and unloaded conditions using DNA Checkerboard. The evaluated connections (SIN, Sistema de Implante Nacional ${ }^{\circledR}$ ) were: 1) external hexagon, 2) internal hexagon, and 3) Morse cone (do Nascimento et al., 2012). In all connections, the titanium abutment screws received a torque of $20 \mathrm{Ncm}$ and the crown received $10 \mathrm{Ncm}$, as recommended by the manufacturer (do Nascimento et al., 2012). After fatigue, the external hexagon and internal hexagon connections showed significantly higher bacterial counts than the Morse cone connection (do Nascimento et al., 2012). When the specimens in the control groups (without loading) were compared with the specimens with loading, the external hexagon and internal hexagon connections of the loaded groups showed significantly higher bacterial counts than their unloaded counterparts (do Nascimento et al., 2012). However, the bacterial counts were not significantly different for the Morse cone connection between the control group (without loading) and the group with loading (do Nascimento et al., 2012).

do Nascimento et al. (2015) evaluated the bacterial infiltration (DNA Checkerboard method) of prostheses supported by external hexagon or Morse cone implants (Signo Vinces ${ }^{\circledR}$ ). do Nascimento et al. (2015) performed mechanical cycling on the specimens ( $150 \mathrm{Ncm}$ during 500,000 cycles at $1.8 \mathrm{~Hz}$ ). Before loading, the titanium abutment screws were tightened to $20 \mathrm{Ncm}$ and the prosthesis screws to $10 \mathrm{Ncm}$ in all connections (manufacturer's recommendation) (do Nascimento et al., 2015). Twenty-one bacterial species, including periodontal pathogens and Candida albicans, were found colonizing the internal surfaces of the external hexagon implants after loading. No microorganisms were detected in the internal parts of the Morse cone implants after loading (do Nascimento et al., 2015). In general, the external hexagon and Morse cone implants showed similar values of marginal gap before and after loading (do Nascimento et al., 2015). The mean values of microgap vertical recorded for all groups were low, ranging from 12 to $25 \mu \mathrm{m}$ (do Nascimento et al., 2015).

da Silva-Neto et al. (2017) compared the Morse cone with external hexagon and internal hexagon based on microleakage. The application of the torques followed the manufacturer's instructions (Neodent ${ }^{\circledR}$ ) (da Silva-Neto et al., 2017). Using toluidine blue and mechanical cycling (300,000 cycles, $50 \mathrm{~N}, 1.2 \mathrm{~Hz})$, da Silva-Neto et al. (2017) found that the Morse cone connection was significantly more effective in preventing microleakage after fatigue than the internal hexagon connection. It is worth mentioning that in this same study, after 300,000 cycles, there was no significant difference based on microleakage between the Morse cone and external hexagon; however lower mean microleakage values were observed for the Morse cone connection (da Silva-Neto et al., 2017). 


\section{Discussion}

In scientific research, different methodologies can generate different results. Despite this, most of the studies evaluated in this review showed that less microleakage was related to the Morse cone connection when compared with the external hexagon and internal hexagon connections.

Few studies included in this review reported the microgap sizes of the evaluated connections (Verdugo et al., 2014; do Nascimento et al., 2015; Pereira et al., 2016). Regardless of the type of connection, the microgap sizes shown in this review ranged from 1.5 to $25 \mu \mathrm{m}$ (Verdugo et al., 2014; do Nascimento et al., 2015; Pereira et al., 2016) and, therefore, these microgap sizes are within the clinically acceptable range (based on implant-abutment interface, an acceptable microgap size should not exceed $120 \mu \mathrm{m}$ ) (do Nascimento et al., 2015). It is worth mentioning that the mean size of microorganism species in the oral microbiota ranges from 1.1 to $1.5 \mu \mathrm{m}$ in diameter and 2 to $6 \mu \mathrm{m}$ in length (do Nascimento et al., 2015). Therefore, bacterial microleakage can be expected in any connection.

Verdugo et al. (2014) and Pereira et al. (2016) reported smaller microgap sizes for the Morse cone connection when compared with external hexagon, which may explain less microleakage related to cone Morse connection in most cases of this review. Scarano et al. (2016b, c) analysed with 3-dimensional X-ray microtomography, the microscopic space that exists between the implant body and abutment, comparing the internal hexagon with Morse cone. It was observed that in all cases for the Morse cone connection there was no detectable separation between implant and abutment. However, for the internal hexagon connection, numerous microgaps and voids were present (Scarano et al., 2016b, c). Thus, the Morse cone connection appears to be more advantageous than the external hexagon and internal hexagon connections.

The Morse cone connection can resist torque loss more significantly after fatigue than the external hexagon connection (Park et al., 2010). Torque loss can significantly facilitate microleakage (Verdugo et al., 2014), and it is speculated that microleakage can reduce torque values (Sahin and Ayyildiz, 2014). Therefore, resisting the loss of torque is very important for the success of the treatment and, therefore, the Morse cone connection can be more advantageous than the external hexagon connection.

Due to the better results of the Morse cone shown in this review (less microleakage), this connection is possibly less likely to generate inflammation of peri-implant tissues (Verdugo et al., 2014). In addition, the design of the Morse cone generates a separation between the microgap and the marginal bone (Weng et al., 2008; Ranieri et al., 2015; Macedo et al., 2016). Therefore, in theory, a microleakage would occur at a greater distance from the peri-implant tissues (when compared with internal hexagon or hexagon external) (Weng et al., 2008; Ranieri et al., 2015); and this would possibly help to prevent infections of the peri-implant tissues. 


\section{Conclusion}

This literature review concluded that, in most cases, the microleakage in the Morse cone connection was lower when compared with the external hexagon and internal hexagon connections.

\section{References}

Brånemark, P. I. (1983) Osseointegration and its experimental background. J. Prosthet. Dent. 50, 399-410.

Brånemark, P. I., Hansson, B. O., Adell, R., Breine, U., Lindström, J., Hallén, O., Ohman, A. (1977) Osseointegrated implants in the treatment of the edentulous jaw. Experience from a 10 -year period. Scand. J. Plast. Reconstr. Surg. 16, 1-132.

Ceruso, F. M., Barnaba, P., Mazzoleni, S., Ottria, L., Gargari, M., Zuccon, A., Bruno, G., Di Fiore, A. (2017) Implant-abutment connections on single crowns: a systematic review. Oral Implantol. (Rome) 10, 349-353.

D’Ercole, S., Scarano, A., Perrotti, V., Mulatinho, J., Piattelli, A., lezzi, G., Tripodi, D. (2014) Implants with internal hexagon and conical implant-abutment connections: An in vitro study of the bacterial contamination. J. Oral Implantol. 40, 30-36.

da Silva-Neto, J. P., Prudente, M. S., Dantas, T. S., Senna, P. M., Ribeiro, R. F., das Neves, F. D. (2017) Microleakage at different implant-abutment connections under unloaded and loaded conditions. Implant Dent. 26, 388-392.

de Sousa, C. A., Conforte, J. J., Caiaffa, K. S., Duque, C., Assunção, W. G. (2019) Sealing agent reduces formation of single and dual-species biofilms of Candida albicans and Enterococcus faecalis on screw joints at the abutment/implant interface. PLoS One 14, e0223148.

Dibart, S., Warbington, M., Su, M. F., Skobe, Z. (2005) In vitro evaluation of the implant-abutment bacterial seal: The locking taper system. Int. J. Oral Maxillofac. Implants 20, 732-737.

do Nascimento, C., Miani, P. K., Pedrazzi, V., Goncalves, R. B., Ribeiro, R. F., Faria, A. C. L., Macedo, A. P., Albuquerque, R. B. (2012) Leakage of saliva through the implant-abutment interface: In vitro evaluation of three different implant connections under unloaded and loaded conditions. Int. J. Oral Maxillofac. Implants 27, 551-560.

do Nascimento, C., Ikeda, L. N., Pita, M. S., Pedroso, R. C., Pedrazzi, V., Albuquerque, R. B. J., Ribeiro, R. F. (2015) Marginal fit and microbial leakage along the implant-abutment interface of fixed partial prostheses: An in vitro analysis using Checkerboard DNA-DNA hybridization. J. Prosthet. Dent. 114, 831-838.

Goiato, M. C., Pellizzer, E. P., da Silva, E. V. F., da Rocha Bonatto, L., dos Santos, D. M. (2015) Is the internal connection more efficient than external connection in mechanical, biological, and esthetical point of views? A systematic review. Oral Maxillofac. Surg. 19, 229-242.

Hernigou, P., Queinnec, S., Flouzat Lachaniette, C. H. (2013) One hundred and fifty years of history of the Morse taper: From Stephen A. Morse in 1864 to complications related to modularity in hip arthroplasty. Int. Orthop. 37, 2081-2088.

Jaworski, M., Laporta, M. Z., Curcio, R., Rossi, L. (2012) Analysis of the bacterial seal at the implant-abutment interface in external-hexagon and Morse taper-connection implants: An in vitro study using a new methodology. Int. J. Oral Maxillofac. Implants 27, 1091-1095.

Khorshidi, H., Raoofi, S., Moattari, A., Bagheri, A., Kalantari, M. H. (2016) In vitro evaluation of bacterial leakage at implant-abutment connection: An 11-degree Morse taper compared to a butt joint connection. Int. J. Biomater. 2016, 8527849.

Macedo, J. P., Pereira, J., Vahey, B. R., Henriques, B., Benfatti, C. A. M., Magini, R. S., López-López, J., Souza, J. C. M. (2016) Morse taper dental implants and platform switching: The new paradigm in oral implantology. Eur. J. Dent. 10, 148-154. 
Merz, B. R., Hunenbart, S., Belser, U. C. (2000) Mechanics of the implant-abutment connection: An 8-degree taper compared to a butt joint connection. Int. J. Oral Maxillofac. Implants 15, 519-526.

Mishra, S. K., Chowdhary, R., Kumari, S. (2017) Microleakage at the different implant abutment interface: A systematic review. J. Clin. Diagn. Res. 11, ZE10-ZE15.

Park, J. K., Choi, J. U., Jeon, Y. C., Choi, K. S., Jeong, C. M. (2010) Effects of abutment screw coating on implant preload. J. Prosthodont. 19, 458-464.

Pereira, J., Morsch, C. S., Henriques, B., Nascimento, R. M., Benfatti, C. A., Silva, F. S., López-López, J., Souza, J. C. M. (2016) Removal torque and biofilm accumulation at two dental implant-abutment joints after fatigue. Int. J. Oral Maxillofac. Implants 31, 813-819.

Ranieri, R., Ferreira, A., Souza, E., Arcoverde, J., Dametto, F., Gade-Neto, C., Seabra, F., Sarmento, C. (2015) The bacterial sealing capacity of Morse taper implant-abutment systems in vitro. J. Periodontol. 86, 5.

Ricomini Filho, A. P., Fernandes, F. S., Straioto, F. G., da Silva, W. J., Del Bel Cury, A. A. (2010) Preload loss and bacterial penetration on different implant-abutment connection systems. Braz. Dent. J. 21, 123-129.

Sahin, C., Ayyildiz, S. (2014) Correlation between microleakage and screw loosening at implant-abutment connection. J. Adv. Prosthodont. 6, 35-38.

Scarano, A., Perrotti, V., Piattelli, A., laculli, F., lezzi, G. (2015) Sealing capability of implant-abutment junction under cyclic loading: A toluidine blue in vitro study. J. Appl. Biomater. Funct. Mater. 13, e293-e295.

Scarano, A., Lorusso, C., Di Giulio, C., Mazzatenta, A. (2016a) Evaluation of the sealing capability of the implant healing screw by using real time volatile organic compounds analysis: Internal hexagon versus cone Morse. J. Periodontol. 87, 1492-1498.

Scarano, A., Valbonetti, L., Degidi, M., Pecci, R., Piattelli, A., de Oliveira, P. S., Perrotti, V. (2016b) Implantabutment contact surfaces and microgap measurements of different implant connections under 3-dimensional X-ray microtomography. Implant Dent. 25, 656-662.

Scarano, A., Mortellaro, C., Mavriqi, L., Pecci, R., Valbonetti, L. (2016c) Evaluation of microgap with threedimensional X-ray microtomography: Internal hexagon versus cone Morse. J. Craniofac. Surg. 27, 682-685.

Schmitt, C. M., Nogueira-Filho, G., Tenenbaum, H. C., Lai, J. Y., Brito, C., Döring, H., Nonhoff, J. (2014) Performance of conical abutment (Morse Taper) connection implants: A systematic review. J. Biomed. Mater. Res. A 102, 552-574.

Tripodi, D., Vantaggiato, G., Scarano, A., Perrotti, V., Piattelli, A., lezzi, G., D’Ercole, S. (2012) An in vitro investigation concerning the bacterial leakage at implants with internal hexagon and Morse taper implantabutment connections. Implant Dent. 21, 335-339.

Verdugo, C. L., Núñez, G. J., Avila, A. A., San Martín, C. L. (2014) Microleakage of the prosthetic abutment/ implant interface with internal and external connection: In vitro study. Clin. Oral Implants Res. $\mathbf{2 5}$ 1078-1083.

Vinhas, A. S., Aroso, C., Salazar, F., López-Jarana, P., Ríos-Santos, J. V., Herrero-Climent, M. (2020) Review of the mechanical behavior of different implant-abutment connections. Int. J. Environ. Res. Public Health 17, 8685 .

Weng, D., Nagata, M. J., Bell, M., Bosco, A. F., de Melo, L. G., Richter, E. J. (2008) Influence of microgap location and configuration on the periimplant bone morphology in submerged implants. An experimental study in dogs. Clin. Oral Implants Res. 19, 1141-1147.

Bittencourt A. B. B. C. et al. 